\title{
The first study of successful pregnancies in Chinese patients with Phenylketonuria
}

Lin Wang ${ }^{1 \dagger}$, Fang $\mathrm{Ye}^{2 \dagger}$, Hui Zou ${ }^{3}$, Kundi Wang ${ }^{2}$, Zhihua Chen ${ }^{4}$, Qin Hui ${ }^{2}$, Bingjuan Han ${ }^{3}$, Chun He${ }^{4}$, Xiaowen $\mathrm{Li}^{5^{*}}$ and Ming Shen ${ }^{2^{*}}$

\begin{abstract}
Background: Since the inception of newborn screening programs in China in the 1990s, pregnancy among patients with inherited, metabolic disorders has become more common. This study explores the management and outcomes of planned, full-term pregnancies in patients with phenylketonuria (PKU).

Method: Married patients with PKU from 2012 to 2017 were enrolled to receive prenatal counseling and regular health assessments. Study-related assessments included the timing of Phe-restricted diets, maternal weight gain, gestational age, pregnancy complications, and blood Phe concentrations (both pre-conception and during pregnancy), obstetrical data, and offspring outcomes(e.g. anthropomorphic measurements and developmental quotients [DQs]).

Results: A total of six offspring were successfully delivered. The mean \pm SD (range) age of the mother at delivery was $26.3 \pm 4.7$ (range: $21.1-32.5$ ) years. The mean duration of Phe control before pregnancy was $5.5 \pm 1.3$ (range: $3.1-$ 6.5) months. During pregnancy, the proportion of blood Phe concentrations within the clinically-recommended target range $(120-360 \mu \mathrm{mol} / \mathrm{L})$ ranged from $63.2-83.5 \%$. Low birth weight $(<2500 \mathrm{~g})$ offspring occurred in two women who experienced suboptimal metabolic control. In addition, offspring DQ was related to the proportion of blood Phe levels per trimester that were within the recommended range $(r=0.886, p=0.016)$.

Conclusion: This is the first report of women in China with PKU who successfully gave birth to clinically healthy babies. Infant outcomes were related to maternal blood Phe management prior to and during pregnancy. In maternal PKU patients with poor compliance to dietary treatment, sapropterin dihydrochloride $\left(6 \mathrm{R}^{-} \mathrm{BH}_{4}\right)$ may be an option to improve the management of blood Phe levels.
\end{abstract}

Keywords: Maternal phenylketonuria, Dietary treatment, Pregnancy, Offspring outcomes, Sapropterin dihydrochloride, $\mathrm{BH} 4$

\section{Background}

Phenylalanine hydroxylase (PAH) deficiency [phenylketonuria (PKU)] is a rare, inherited, metabolic disease that can result in high blood phenylalanine (Phe)

\footnotetext{
*Correspondence: lixiaowen7080@126.com; shenming26@msn.com

${ }^{+}$Lin Wang and Fang Ye contributed equally to this work.

${ }^{5}$ Department of Nutrition, China-Japan Friendship Hospital, No. 2, Yinghua East Street, Chaoyang district, Beijing 100029, China

${ }^{2}$ Department of Pediatrics, China-Japan Friendship Hospital, No. 2, Yinghua East Street, Chaoyang district, Beijing 100029, China

Full list of author information is available at the end of the article
}

concentrations that are toxic to the brain. Chronic hyperphenylalaninemia (HPA) can lead to mental disabilities and neuropsychological abnormalities [1]. Early diagnosis and adequate metabolic management of blood Phe concentrations greatly improve the prognosis and quality of life of patients with PKU $[1,2]$. Newborn screening (NBS) programs for the detection of HPA were introduced during the 1960's in western countries and during the 1990's in China [3,4] when a pilot program was initiated [5]. Over the past 30 years, early

C C The Author(s). 2020 Open Access This article is licensed under a Creative Commons Attribution 4.0 International License, which permits use, sharing, adaptation, distribution and reproduction in any medium or format, as long as you give appropriate credit to the original author(s) and the source, provide a link to the Creative Commons licence, and indicate if changes were made. The images or other third party material in this article are included in the article's Creative Commons licence, unless indicated otherwise in a credit line to the material. If material is not included in the article's Creative Commons licence and your intended use is not permitted by statutory regulation or exceeds the permitted use, you will need to obtain permission directly from the copyright holder. To view a copy of this licence, visit http://creativecommons.org/licenses/by/4.0/ The Creative Commons Public Domain Dedication waiver (http://creativecommons.org/publicdomain/zero/1.0/) applies to the data made available in this article, unless otherwise stated in a credit line to the data. 
diagnosis and treatment of a number of Chinese patients with PKU has resulted in nearly normal intellectual and physical development [6]. Some of these treated female PKU patients have now reached childbearing age. However, due to cultural issues, marriage is less common among female patients with PKU in China compared to unaffected adults.

The offspring of pregnant patients with PKU are at risk for post-natal complications because elevated maternal blood Phe is associated with teratogenicity $[7,8]$. In these cases, there is a higher risk for low birth weight, microcephaly, facial dysmorphism, mental retardation, and intrauterine and/or postnatal growth restriction. In addition, elevated maternal blood Phe has been associated with the embryogenesis of heart defects [7]. All of these risks can be reduced with proper nutritional supplements and management of blood Phe levels prior to and throughout pregnancy $[9,10]$. The suggested target range for blood Phe is $120-360 \mu \mathrm{mol} / \mathrm{L}$, as established by the Maternal Phenylketonuria Collaborative Study (MPKUCS) [8, 11]. Moreover, blood Phe variability within that range should also be avoided in order to obtain optimal offspring outcomes $[9,12]$.

There is little research in the literature to describe pregnancy outcomes to help guide physicians and obstetricians with the management of pregnant women with rare diseases in China. One case study has been published of a Chinese woman with methylmalonic aciduria (MMA) and homocystinuria, cblC type, who reportedly delivered a healthy child [13]. The purpose of this study is to describe the pregnancy, delivery, and offspring outcomes for 10 patients with PKU in China, along with an evaluation of the effect of timing and duration of diet, routine nutritional assessments, and other medical interventions.

\section{Material and methods Patients and pregnancy}

All patients with PKU married between 2012 and 2017 were recalled to healthcare centers within China to receive prenatal counseling and education and to receive regular clinical evaluations. Marriage partners were screened for heterozygous PAH genes. As an autosomal recessive disorder, all offspring of women with PKU will carry at least one abnormal gene for PKU, which is inherited from their homozygous-affected mother. Therefore, genetic counseling was provided to all women with PKU in this study prior to conception. Written consent was obtained from each affected woman during the genetic counseling. After genetic counseling, all of the affected patients were advised to maintain blood phenylalanine (Phe) levels to less than $360 \mu \mathrm{mol} / \mathrm{L}$ for at least 3 months prior to conception and to maintain blood Phe between 120 and $360 \mu \mathrm{mol} / \mathrm{L}$ during pregnancy. In order to obtain optimal pregnancy outcomes, patient education included the calculation of Phe intake in order to for patients to maintain blood Phe within the clinically-acceptable blood Phe target range $(120-360 \mu \mathrm{mol} / \mathrm{L})$ while sustaining adequate nutrition for the developing fetus.

Study-related assessments included the timing of Pherestricted diets, maternal weight gain, gestational age, pregnancy complications, and blood Phe concentrations (both pre-conception and during pregnancy). During the pregnancy, all the affected women received at least five ultrasound examinations: two in the first trimester, two in the second, and one in the third for structural abnormality screening, especially focusing on the growth rate of head circumference and physical growth. During 2426 weeks of gestational age, fetal echocardiography was conducted for screening of severe congenital heart malformations. In addition, all the affected women were advised to visit their local antenatal care service at least once a month during the first and the second trimester: two visits every month during the third trimester, and one visit every week after the 37th gestational week. Local obstetricians measured and recorded weight gain, body mass index, uterine height, and abdominal circumference measurements to assess the physical growth of the fetus.

\section{Visits and/or interviews}

Mothers were interviewed in person (if patients were located within Beijing area), by telephone, WeChat (a popular social media platform in China), or referred to local centers (if patients were located outside of the Beijing area). Interviewers discussed current diets and other medical concerns. Usual care consisted of biweekly to monthly communication with a metabolic nutritionist to review diet, weight and weight gain, dietary Phe intake calculations, and calorie counts. Dietary changes were advised based on the degree of metabolic control, derived from fasting plasma Phe concentrations, and maternal weight gain.

\section{Fasting plasma Phe concentration}

At the patient's local hospital, fasting blood Phe concentrations were measured weekly prior to conception and twice a week during pregnancy with all data recorded in pregnancy diaries. Blood Phe was measured by highpressure liquid chromatography (HPLC) using tandem mass spectrometry. An overall review of blood Phe results was used for the assessment of maternal adherence to a Phe-restricted diet during pregnancy.

\section{Nutrition}

Throughout their planned conception and pregnancy, patients were asked to keep a daily record of all food 
and beverages consumed so that quantities of low-Phe and Phe-free synthetic protein, dietary Phe, calories, and fluid intake volume could be derived. Laboratory examinations included plasma amino acids, hemoglobin and hematocrit, prealbumin, and iron. A nutritionist reviewed the dietary records and provided advice to patients every 2 weeks.

\section{Offspring outcomes}

After birth, offspring anthropomorphic assessments consisted of gender, weight, length, and occipitofrontal circumference (OFC). Neuropsychometric assessments for offspring consisted of development quotient (DQ) measurements using the Gesell Child Developmental Age Scale [14].

\section{Statistical analysis}

Statistical analysis was performed using Statistical Package for the Social Sciences (SPSS) for Windows, version 15.0 (SPSS Inc., Chicago, IL, USA). Descriptive analysis of demographic characteristics was conducted with calculation of means and standard deviations for continuous variables, and proportions for categorical variables. Data were expressed as mean \pm SD unless indicated otherwise. Spearman correlations were conducted between DQ and the mean proportion of blood Phe levels per trimester that were within the recommended range. A $p$-value $<0.05$ was considered to be statistically significant (Additional file 1).

\section{Results}

\section{Patients' demographics}

As one of the national healthcare centers in China, our unit has diagnosed and treated more than 2930 patients with HPA since 1984. By the end of 2017, a total of 172 female patients reached 20 years of age and 10 were married. Four of 10 were diagnosed by NBS, five were diagnosed symptomatically within their first year of life, and one was diagnosed at 26 years of age after delivering a baby with a congenital anomaly. The patients originated from Shanxi, Tianjin, Hebei, Shandong provinces or from the Beijing municipality and were all of Han nationality. None of their partners carried PAH heterozygous genes. In terms of educational attainment, two of the mothers graduated from middle school, three graduated from high school, and one attended college. Demographics for this cohort are listed in Table 1.

\section{Pregnancy, delivery and offspring outcomes}

By the end of 2017, six of the 10 women had become pregnant: four of them had a single pregnancy, one had two pregnancies, and one had three pregnancies. The mean age at pregnancy was $26.3 \pm 4.7$ years and all patients had initiated a Phe-restricted diet during pre-
Table 1 Maternal Demographics of Cohort

\begin{tabular}{ll}
\hline Maternal patients with PKU $(n=6)$ & Mean $\pm S D$, range or $\mathrm{n}(\%)$ \\
\hline Age at pregnancy $(\mathrm{Yrs})$ & $26.3 \pm 4.7$ \\
Educational attainments (Yrs) & $12.1 \pm 2.1$ \\
Marital status & Married \\
Nationality & Han \\
Initial Phe concentration $(\mu \mathrm{mol} / \mathrm{L})$ & $1095.8-2342.9$ \\
Classification & Classical PKU $(N=5)$ \\
Diet pre- or after conception & Mild PKU $(N=1)$ \\
\hline
\end{tabular}

conception. The condition during pregnancy was generally normal without anemia, gestational hypertension, or other severe complications (Table 2). Five of the deliveries were vaginal and one was delivered by cesarean section. The mean blood Phe levels were: $478.3 \pm$ $181.6 \mu \mathrm{mol} / \mathrm{L}, \quad 193.7 \pm 84.8 \mu \mathrm{mol} / \mathrm{L}, \quad$ and $\quad 151.4 \pm$ $96.9 \mu \mathrm{mol} / \mathrm{L}$ for the first, second, and third trimester, respectively. Maternal weight change was $11.5 \pm 2.6$ (9.215.0) $\mathrm{kg}$. Hemoglobin and hematocrit values were normal. (See Supplementary Material).

Six maternal patients with PKU successfully delivered 6 babies, 5 males and 1 female. The mean gestation period was $38.2 \pm 0.6$ (range: $37.4-39.1$ ) wks. Table 3 summarizes the effect of treatment in terms of birth weight, length, and OFC-B. The mean birth weight, mean birth length and mean OFC-B were $2888.3 \pm 388.1$ (range: 2350.0-3300.0) g, $49.7 \pm 2.3$ (range: 46.6-53.0) $\mathrm{cm}$, and $33.4 \pm 1.1$ (range: $31.5-34.5$ ) $\mathrm{cm}$ respectively. All offspring were born full-term without congenital heart defects or other severe malformations (Table 3). Mean blood Phe levels were maintained within the recommended range $(120-360 \mu \mathrm{mol} / \mathrm{L})$ during the 3rd trimester of pregnancy (Fig. 1).

For this cohort, both offspring birth weights and DQ assessments were found to be related to maternal Phe control during pregnancy. Low birth weight $(<2500 \mathrm{~g})$ offspring occurred in two women (Patients No. 2 and No.3) who experienced suboptimal metabolic control during pregnancy. Two low birth weight neonates (range: 2350-2480 g) were offspring of Patients No. 2 and No.3 who had $<70 \%$ of blood Phe measurements within range during pregnancy. These same two women gave birth to offspring with lower DQ assessments (DQ range: 80.6 to 85.7 ). Overall, the $\mathrm{DQ}$ of infants correlated with the proportion of blood Phe levels per trimester that were within the recommended range $(r=0.886$, $p=0.016)$.

\section{Patient 1}

Patient No. 1 originated from Tianjin, was diagnosed with mild PKU, and was the first patient from our clinic who married. Genetic analysis showed the presence of a 
Table 2 Maternal Blood Phe, Age, Negative Events, Delivery, Weight Gain, and Origin

\begin{tabular}{|c|c|c|c|c|c|c|c|c|}
\hline $\begin{array}{l}\text { Patient } \\
\text { No. }\end{array}$ & $\begin{array}{l}\text { Initial } \\
\text { Phe } \\
\text { Conc. }\end{array}$ & $\begin{array}{l}\text { Age at } \\
\text { pregnancy } \\
\text { (Yrs) }\end{array}$ & $\begin{array}{l}\text { Treatment }{ }^{\mathrm{a}} \text { Prior to } \\
\text { pregnancy (months) }\end{array}$ & $\begin{array}{l}\text { Proportion of Blood Phe } \\
\text { within Range }{ }^{\mathrm{b}}(\%)\end{array}$ & $\begin{array}{l}\text { Previous } \\
\text { Negative } \\
\text { events }\end{array}$ & $\begin{array}{l}\text { Mode of } \\
\text { delivery }\end{array}$ & $\begin{array}{l}\text { Weight gain } \\
\text { During } \\
\text { pregnancy } \\
(\mathrm{kg})\end{array}$ & $\begin{array}{l}\text { China } \\
\text { Municipality or } \\
\text { Province }\end{array}$ \\
\hline 1 & 1089.7 & 28.3 & 3.1 & 75.0 & 1 & $\begin{array}{l}\text { vaginal } \\
\text { delivery }\end{array}$ & 12.0 & Tianjin \\
\hline 2 & 1210.8 & 21.1 & 5.0 & 66.7 & 0 & $\begin{array}{l}\text { vaginal } \\
\text { delivery }\end{array}$ & 9.2 & Shanxi \\
\hline 3 & 1278.0 & 32.5 & 6.0 & 35.1 & $\begin{array}{l}2 \text { negative } \\
\text { events }^{c}\end{array}$ & $\begin{array}{l}\text { vaginal } \\
\text { delivery }\end{array}$ & 9.5 & Hebei \\
\hline 4 & 1755.7 & 30.2 & 6.3 & 87.5 & 0 & $\begin{array}{l}\text { Cesarean } \\
\text { section }\end{array}$ & 9.3 & Beijing \\
\hline 5 & 1937.3 & 21.6 & 5.9 & 80.2 & 1 & $\begin{array}{l}\text { vaginal } \\
\text { delivery }\end{array}$ & 15.0 & Shandong \\
\hline 6 & 1574.0 & 23.9 & 6.5 & 78.7 & 0 & $\begin{array}{l}\text { vaginal } \\
\text { delivery }\end{array}$ & 14.2 & Shandong \\
\hline
\end{tabular}

: (by telephone or we-chat)

: Blood Phe clinically-recommended target range $(120-360 \mu \mathrm{mol} / \mathrm{L})$

c: For Patient No. 3, the first pregnancy terminated by spontaneous abortion; the second pregnancy was voluntarily aborted due to hyperphenylalaninemia

PAH gene mutation (allele) c.1238G $>$ C(p.R413P)/ c.1238G > C(p.R413P). This patient initiated a Pherestricted diet 3.1 months prior to becoming pregnant. She learned how to count dietary protein and Phe intake from each meal during the 3 months and filled three diaries during pregnancy. Baseline blood Phe was $489.7 \mu \mathrm{mol} / \mathrm{L}$. She lived in Tianjin city and came to the clinic every 2 weeks. Blood Phe levels were mostly stable during all three trimesters of her pregnancy. The mean proportion of blood Phe levels per trimester that were within the recommended range were 55.6, 73.9 and 95.5\% during the 1st trimester, 2nd trimester and 3rd trimester, respectively. After a full-term pregnancy, she gave birth to a healthy, male baby weighing $3050 \mathrm{~g}$ and measuring $52 \mathrm{~cm}$ in length. The infant developed normally, the DQ assessment was 88.2.

\section{Patient 2}

Patient No.2 originated from Shanxi province and genetic analysis showed a PAH gene mutation (allele) c.728G > A(p.R243Q)/c.838G > A(p.E280K). This patient initiated dietary treatment 5.0 months prior to becoming pregnant. Baseline blood Phe was $523.9 \mu \mathrm{mol} / \mathrm{L}$. Even though dietary management education was provided, she and her family didn't fully comply with a Phe-restricted diet during the first period of pregnancy. Because of a financial burden, she didn't have frequent blood examinations at hospital visits. This patient had high blood Phe concentrations during her first trimester (605.4$908.1 \mu \mathrm{mol} / \mathrm{L}$ for 6 weeks) which resulted in a dramatic change in blood Phe when the first trimester is compared to the third trimester. The proportion of blood Phe levels per trimester that were within the recommended range were 36.2, 66.3 and $92.7 \%$, respectively. Patient No. 2 delivered a male baby with a gestational age of $38^{+1} \mathrm{~W}$ with a low birth weight: $2350 \mathrm{~g}$, birth length: $46.6 \mathrm{~cm}$, and a remarkably smaller OFC-B 31.5 $\mathrm{cm}$. Gesell assessment revealed that the infant had mild language and fine motor development delays and a DQ assessment of 80.6 at nearly 3 years of age.

\section{Patient 3}

Patients No.3 was late diagnosed at 28 years old, when she delivered a baby with cardiac anomalies of Tetralogy of Fallot. Initial maternal blood Phe was $1278.0 \mu \mathrm{mol} / \mathrm{L}$ and genetic analysis showed a PAH gene mutation

Table 3 Offspring Age, Anthropomorphic Assessments, and Developmental Quotients (DQs)

\begin{tabular}{llllllll}
\hline $\begin{array}{l}\text { Offspring } \\
\text { No. }\end{array}$ & Gestational age (weeks + days) & Age (months) & Gender & Birth weight $(\mathrm{g})$ & Birth Length $(\mathrm{cm})$ & Head circumference (cm) & DQs \\
\hline 1 & $38+2$ & 38.2 & male & 3050 & 50.2 & 34.0 & 88.2 \\
2 & $38+1$ & 34.0 & male & 2350 & 46.6 & 31.5 & 80.6 \\
3 & $38+4$ & 19.3 & female & 2480 & 48.0 & 33.0 & 35.7 \\
4 & $39+1$ & 14.7 & female & 2950 & 48.9 & 34.3 & 98.8 \\
5 & $37+3$ & 14.5 & male & 3300 & 51.5 & 34.5 & 96.5 \\
6 & $37+6$ & 7.3 & male & 3200 & 53.0 & & 34.0 \\
\hline
\end{tabular}




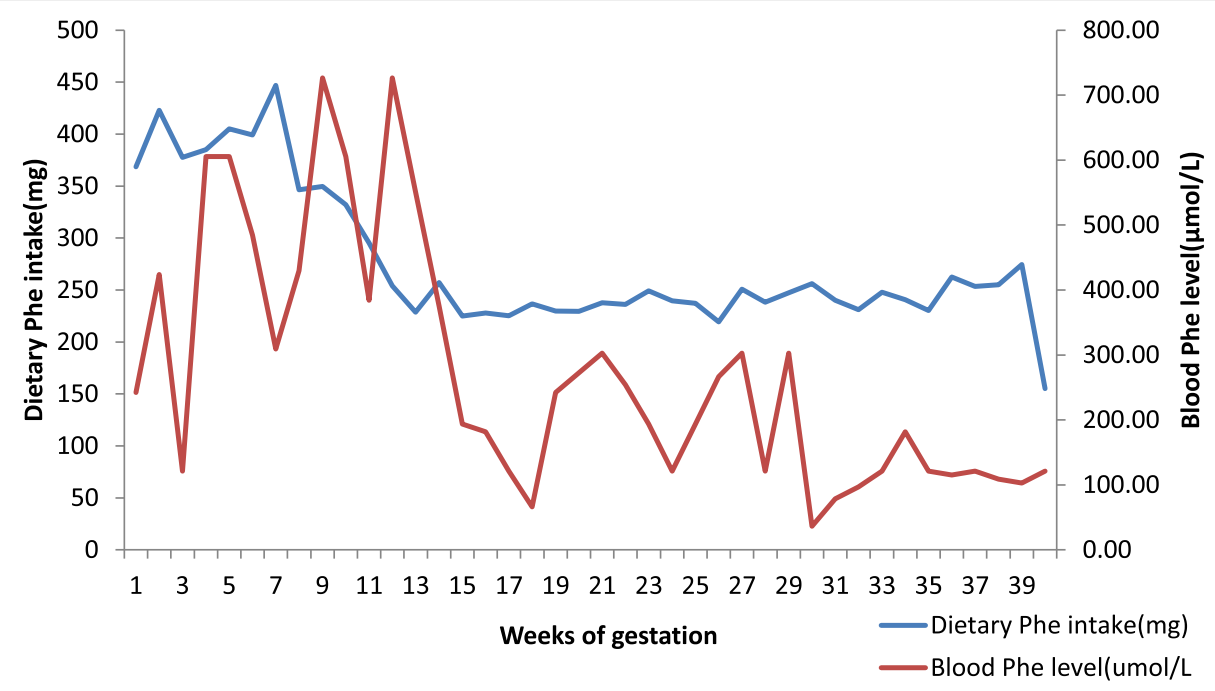

Fig. 1 Mean blood Phe Concentrations and Mean Dietary Phe intake for a Cohort of Women with PKU

(allele) c.728G > A(p.R243Q)/c.728G > A(p.R243Q). Patient No. 3 lived in rural area of Hebei Province and had exhibited yellow hair color from childhood. She had 8 years of education, but failed to graduate from middle school. She could communicate on simple daily issues, but the Wechsler Adult Intelligence Scale (WAIS) indicated moderate mental retardation. She married at 26 years of age. Her second pregnancy was electively aborted due to lack of blood Phe control. She came to our hospital for genetic counseling and started dietary treatment 6 months before her third pregnancy. Baseline blood Phe was $622.1 \mu \mathrm{mol} / \mathrm{L}$. In order to decrease her blood Phe level rapidly, this patient kept a very strict diet and limited dietary protein intake. The fetus demonstrated intrauterine growth restriction likely due to the poor maternal nutritional status in the first trimester. After improving blood Phe control during the second and trimester, Patient No. 3 delivered a male baby with a gestational age of $38^{+4}$ and a low birth weight $(2480 \mathrm{~g})$. The baby exhibited feeding difficulties during the first 6 months and had a weight of $6950 \mathrm{~g}$ at 1 year of age. After feeding patterns were corrected, the infant reached 9000 $\mathrm{g}$ at 19 months and a DQ assessment of 85.7.

\section{Patient 4}

Patient No.4 was a native of Beijing and maternal baseline blood Phe was $460.3 \mu \mathrm{mol} / \mathrm{L}$ and genetic analysis showed a PAH gene mutation (allele) c.1222C > $\mathrm{T}(\mathrm{R} 408 \mathrm{~W}) / \mathrm{c} .975 \mathrm{C}>\mathrm{G}(\mathrm{Y} 325 \mathrm{X})$. She was the only one of this pregnancy cohort who attended college. Patient No.4 married at 29 years of age and implemented recommended dietary treatment immediately after marriage. The patient balanced maternal nutrition with blood Phe control and had frequent inquiries and visits with a specialist in obstetrics and metabolic diseases.
Blood Phe concentrations were within the recommended range $87.5 \%$ of the time during pregnancy. A healthy female baby was delivered with a gestational age of $39+1$ weeks by Cesarean section. The infant was presented for follow-up checkups every month during the first 6 months and every 3 months thereafter, demonstrated normal growth and development milestones, and the DQ assessment was 98.8.

\section{Patient 5}

The first pregnancy of Patient no. 5 was spontaneously aborted at 9 weeks due to arrested fetal development. Patient No. 5 originated from Shandong Province and genetic analysis showed a PAH genetic mutation (allele) c.1238G > C(p.R413P)/c.782G > A(p.R261Q).. Patient No. 5 lived in Jinan city where there is a local metabolic center and had a second pregnancy after dietary treatment for 5.9 months. She visited a local specialist every 1-2 weeks and visited our clinic every 1-2 months. The entire pregnancy went smoothly and the patient maintained $80.2 \%$ of blood Phe levels within the recommended range. Patient No. 5 gave birth to a male baby with a gestational age of $37^{+3}$ Wks. The infant was feeding well and growth data was around $60 \%$ percentile from birth to 1 year old. The DQ assessment was 92.5.

\section{Patient 6}

Patient No. 6 had maternal PKU, originated from Shandong province, and genetic analysis showed a PAH gene mutation (allele) c.1068C > A(p.Y356X)/c.1045 T > G(p.S349A). She was one of patients from our clinic who was among the last to marry. She was on Pherestricted diets 6.5 months prior to becoming pregnant and her baseline blood Phe was $348.6 \mu \mathrm{mol} / \mathrm{L}$. She received consultations from a local center and our clinic. 
Blood Phe levels were well-controlled and were maintained within the recommended range $89.5 \%$ of the time, and was one of the most stable patients in our clinic cohort. Patient No. 6 gave birth to a healthy male baby with a gestational age of $37+6 \mathrm{Wks}$. The infant developed normally with a weight of $8.9 \mathrm{~kg}$ and length of 69.7 $\mathrm{cm}$ at 7.3 months of age. The DQ assessment was 96.2.

\section{Discussion}

Even though several reports on the maternal management of inherited diseases in western countries have been published $[11,15,16]$, a new group of adults in China, identified by NBS with HPA, have just reached child-bearing age. To our knowledge, this study is the first report of a small cohort of pregnant women with PKU and their offspring outcomes in China. Their lessons of dietary Phe, education, and clinical management during pregnancy will provide an important clinical resource.

Maternal PKU syndrome refers to the teratogenic effects of elevated maternal blood phenylalanine during pregnancy [7]. Elevated phenylalanine impairs neurotransmitter synthesis and activity, produces oxidative stress, and is directly toxic to the brain [17]. Some of the signs and symptoms of maternal PKU may be evident at birth but other signs are delayed and only observed over the course of individual growth and development [18, 19]. The Maternal PKU Collaborative Study reported that microcephaly, facial dysmorphology, congenital heart defects, and intrauterine and postnatal growth retardation are risks for the offspring of women with PKU [7, 8]. Indeed, Patient No.3 was first diagnosed with PKU after she gave birth to a baby with cardiac anomalies of Tetralogy of Fallot following a pregnancy without dietary management or metabolic control of blood Phe concentrations. This type of complication can be prevented if a low-phenylalanine diet is maintained prior to, and throughout, pregnancy.

In this study, six maternal patients started a Pherestricted diet from 3.1 months to 6.5 months prior to conception and successfully delivered six healthy babies - demonstrating that metabolic control during pregnancy is beneficial. Previous studies have shown the effect of the degree of blood Phe variability on maternal offspring outcomes. The investigators found strong negative correlations with IQ scores and blood Phe variation at 4, 8 and 14 years suggesting that ideal blood Phe should be both consistent and within the recommended range [12]. Our study confirmed a similar trend between blood Phe and DQ. Patients No.2 and No.3, whose proportion of blood Phe values within the target range was lower than $70 \%$, had progeny with lower DQs compared to the offspring of mothers who had between 75 to
$87.5 \%$ of blood Phe measurements within the 120 $360 \mu \mathrm{mol} / \mathrm{L}$ target range.

Although patients with HPA were strongly encouraged to seek frequent counseling from a metabolic nutritionist to achieve optimum metabolic control, there are still women who live in rural areas who failed to come to clinic or were unable to follow-up in a timely manner, such as Patients No.2 and No.3. The MPKUCS study recommended twice-weekly blood Phe measurements prior to conception and thrice-weekly measurements afterwards $[8,9]$. However, we are aware that Patient No. 3 was monitored every $2-3$ weeks in the second trimester and Patient No.2 was examined as infrequently as monthly during the whole conception period, despite considerable fluctuations in blood Phe concentrations. The frequency of both monitoring blood Phe concentrations and interview visits was clearly inadequate for this patient, which resulted in a high degree of fluctuation of blood Phe levels and to the subsequent impairment to the offspring. Low birth weights (i.e., $2350 \mathrm{~g}$ and $2480 \mathrm{~g}$ ) were observed for offspring from Patients No. 2 and No. 3 , respectively. The offspring for Patient No.3 also presented with postnatal feeding difficulties and growth retardation in the first year, which had also been reported by the MPKUCS $[12,20]$.

Upon investigation, we found several reasons for inadequate prenatal care and suboptimal metabolic control. First, not all local hospitals have a multi-disciplinary team comprised of a biochemical geneticist and a nutritionist. Therefore, some patients were unable to receive immediate, knowledgeable PKU management advice. Second, some patients' adherence to a Phe-restricted diet led to insufficient prenatal nutrition. For example, in order to keep the Phe concentration within the normal range, Patient No.3 was too strict with her diet, which resulted in a weight loss of $5 \mathrm{~kg}$ during the first trimester and subsequent heavy hyperemesis gravidarum and intrauterine growth restriction within the first trimester. This same patient failed to increase her weight until the third trimester. Third, proper medical care of maternal PKU is associated with a cost-prohibitive financial burden. As we published previously [21], many patients suffer a heavy financial burden in certain provinces where there are no government policies for medical reimbursement. For Patient No.2, the cost of frequent visits and examinations likely deterred her from regular attendance at follow-up clinic visits. Finally, sapropterin dihydrochloride (6R-BH4) has not yet been approved for use during pregnancy and this drug was considered cost -prohibitive to all six patients (even though some of them may have benefited from the drug due to poor compliance with dietary treatment). In maternal PKU patients with poor compliance to dietary treatment, sapropterin dihydrochloride $\left(6 \mathrm{R}-\mathrm{BH}_{4}\right)$, has 
been shown to improve the management of blood Phe levels in responsive patients [22-24].

This is the first study on reproductive outcome in patients with PKU after 20 years of follow-up in China. Maternal and offspring data was recorded from the prenatal period to offspring for up to 3 years of postnatal age. One of the limitations of this study was that six cases of pregnancy is a relatively small cohort and more cases are suggested for future studies. Another limitation was the relatively short follow-up period for infants, whose median postnatal age was 17 months. A longitudinal follow-up study would provide more information related to the duration of any detrimental neurological impacts.

These results indicate that a greater effort is warranted to assist women with PKU to remain on a Phe-restricted diet during their reproductive years. Despite clinical management approaches, PKU can exert a high burden on patients, caregivers, and society. This burden of PKU includes social (e.g., marriage bias, poor social relationships), economic (e.g., cost, clinical compliance, and availability of low-Phe diet), and other burdens associated with a lifelong chronic disease. A national association like MCPKUS and a national guideline to optimize maternal PKU care are urgently needed in order to share experiences and best practices between hospitals and practitioners. The goal of this information sharing would be to increase the awareness of metabolic conditions and factors on offspring outcomes. The ideal clinical team would include a perinatologist, a neonatologist, and other genetic and metabolic specialists who would work together to manage patients with high-risk pregnancies. Rural PKU patients may be able to receive counseling from experienced geneticists and nutritionists remotely using the internet. Additional therapeutic options for blood Phe control (e.g.:6R-BH4) should be considered, and made available in the clinic, especially for the patients with poor compliance to dietary treatment $[22,23]$.

\section{Conclusion}

This is the first report of women in China with PKU who successfully gave birth to clinically healthy babies. Infant outcomes were related to maternal blood Phe management prior to and during pregnancy. In maternal PKU patients with poor compliance to dietary treatment, sapropterin dihydrochloride $\left(6 \mathrm{R}-\mathrm{BH}_{4}\right)$ may be an option to improve the management of blood Phe levels.

\section{Supplementary information}

Supplementary information accompanies this paper at https://doi.org/10. 1186/s12884-020-02941-9.

Additional file 1.

\section{Abbreviations}

DQ: Developmental Quotient; HAP: Hyperphenylalaninemia; HPLC: HighPressure Liquid Chromatography; MMA: Methylmalonic Aciduria; MPKUCS: Maternal Phenylketonuria Collaborative Study; NBS: Newborn Screening; OFC: Occipitofrontal Circumference; PAH: Phenylalanine Hydroxylase; PKU: Phenylketonuria; SPSS: Statistical Package for the Social Sciences; WAIS: Wechsler Adult Intelligence Scale

\section{Acknowledgments}

The authors wish to thank all of the women with PKU, their partners, and their offspring for their participation and involvement in our Maternal PKU Program including permission to use their clinical information. We thank the staff of the newborn screening centers who were involved with the

recruitment and data collection processes. We also want to acknowledge the local PKU healthcare centers. Finally, the authors extend a sincere thanks to BioMarin Pharmaceutical Inc. for providing useful information and for providing support for medical editing services for the manuscript.

\section{Authors' contributions}

LW and FY participated in study designing and data collection, data analysis and interpretation, preparation and writing a Manuscript. $\mathrm{HZ}, \mathrm{BJH}, \mathrm{ZHC}$, and $\mathrm{CH}$ participated data analysis and interpretation, preparation and writing Manuscript. KDW and QH participated interpretation of the data and manuscript preparation, and XWL and MS supervised the study and participated in designing the study, data analysis, manuscript writing \& final editing of the study. All authors have read and approved the final manuscript.

\section{Funding}

The study was supported by grants from the China-Japan Friendship Hospital Youth Science and Technology Excellence Project (Grant number: 2014QNYC-A-07) and China-Japan Friendship Hospital Project (Grant number: 2013-MS-25).

\section{Availability of data and materials}

The datasets used and/or analyzed during the current study are available as supplemental materials.

\section{Ethics approval and consent to participate}

The study protocol and data collection instruments were approved by the ethical review boards of China-Japan Friendship Hospital (No. ZRLW 2015-4). Written informed consent for each affected patient was obtained during the genetic counseling in the healthcare center.

\section{Consent for publication}

Written consent for publication was obtained from each patient for use of individual information.

\section{Competing interests}

The authors declare that they have no competing interests.

\section{Author details}

'Department of Preventive Health Care, China-Japan Friendship Hospital, No. 2, Yinghua East Street, Chaoyang district, Beijing 100029, China. ${ }^{2}$ Department of Pediatrics, China-Japan Friendship Hospital, No. 2, Yinghua East Street, Chaoyang district, Beijing 100029, China. ${ }^{3}$ Newborn Screening Center, Jinan Maternity and Child Care Hospital, Jinan, Shandong, China. ${ }^{4}$ Clinical Research Institute, China-Japan Friendship Hospital, No. 2, Yinghua East Street, Chaoyang district, Beijing 100029, China. ${ }^{5}$ Department of Nutrition,

China-Japan Friendship Hospital, No. 2, Yinghua East Street, Chaoyang district, Beijing 100029, China.

Received: 7 July 2019 Accepted: 13 April 2020

Published online: 28 April 2020

References

1. Blau N, van Spronsen FJ, Levy HL. Phenylketonuria. Lancet. 2010;376:141727.

2. Guthrie R, Susi A. A simple phenylalanine method for detecting phenylketonuria in large populations of newborn infants. Pediatrics. 1963;32: 338-43. 
3. Chen RG, Chen HY, Shi SZ, Bai NQ, Ding XJ, Ding Y, et al. Preliminary report on neonatal screening for hypothyroidism, phenylketonuria and galactosemia. Shanghai Medical Journal1983;6:344-346.

4. Shi XT, Cai J, Wang YY, Tu WJ, Wang WP, Gong LM, et al. Newborn screening for inborn errors of metabolism in mainland China: 30 years of experience. JIMD Rep. 2012;6:79-83.

5. Mei L, Song P, Xu L. Newborn screening and related policy against phenylketonuria in China. Intractable Rare Dis Res. 2013;2:72-6.

6. Shen M. Paying more attention to the prevention and treatment of maternal phenylketonuria. Chin J Appl Clin Pediatr. 2016;31(20):1521-4.

7. Lenke RR, Levy HL. Maternal phenylketonuria and hyperphenylalaninemia: an international survey of the outcome of untreated and treated pregnancies. N Engl J Med. 1980;303:1202-8.

8. Koch R, Hanley W, Levy H, Matalon K, Matalon R, Rouse B, et al. The maternal phenylketonuria international study: 1984-2002. Pediatrics. 2003; 112:1523-99.

9. Widaman KF, Azen C. Relation of prenatal phenylalanine exposure to infant and childhood cognitive outcomes: results from the international maternal PKU collaborative study. Pediatrics. 2003;112:1537-43.

10. Langendonk JG, Roos JC, Angus L, Williams M, Karstens FP, de Klerk JB, et al. A series of pregnancies in women with inherited metabolic disease. J Inherit Metab Dis. 2012;35:419-24.

11. Andersson HC. 50 years ago in the journal of pediatrics: children of mothers with phenylketonuria. Pediatrics. 2013;163:671.

12. Maillot F, Lilburn M, Baudin J, Morley DW, Lee PJ. Factors influencing outcomes in the off spring of mothers with phenylketonuria during pregnancy: the importance of variation in maternal blood phenylalanine. Am J Clin Nutr. 2008:88:700-5.

13. Liu YP, Wang Q, Li XY, Ding Y, Song JQ, Yang YL. First Chinese case of successful pregnancy with combined methylmalonicaciduria and homocystinuria, cblC type. Brain Dev. 2015;37:286-91.

14. Conoley JC, Impera JC. Gesell Child Developmental Age Scale. The Twelfth Mental Measurements Yearbook; 1995.

15. Aubard Y, Darodes N, Cantaloube M. Hyperhomocysteinemia and pregnancy - review of our present understanding and therapeutic implications. Eur J Obstet Gyncol Reprod Biol. 2000;93:157-65.

16. Levy HL. Historical background for the maternal PKU syndrome. Pediatrics. 2003;112:1516-8

17. Rausell D, García-Blanco A, Correcher P, Vitoria I, Vento M, Cháfer-Pericás C. Newly validated biomarkers of brain damage may shed light into the role of oxidative stress in the pathophysiology of neurocognitive impairment in dietary restricted phenylketonuria patients. Pediatr Res. 2019 Jan;85(2):242-50.

18. Waisbren SE, Hanley W, Levy HL, Shifrin H, Allred E, Azen C, Chang PN, Cipcic-Schmidt S, de la Cruz F, Hall R, Matalon R. Outcome at age 4 years in offspring of women with maternal phenylketonuria: the maternal PKU collaborative study. JAMA. 2000 Feb 9;283(6):756-62.

19. Rouse B, Azen C. Effect of high maternal blood phenylalanine on offspring congenital anomalies and developmental outcome at ages 4 and 6 years: the importance of strict dietary control preconception and throughout pregnancy. J Pediatr. 2004;144(2):235-9. https://doi.org/10.1016/j.jpeds.2003.10.062

20. Platt LD, Koch R, Hanley WB, Lew HL, Matalon R, Rouse B, et al. The international study of pregnancy outcome in women with maternal phenylketonuria: report of a 12 year study. Am J Obstet Gynecol. 2000;182:326-33.

21. Wang L, Zou H, Ye F, Wang KD, Li XW, Chen ZH, et al. Household financial burden of phenylketonuria treatment in China: a cross-sectional study. J Inherit Metab Dis. 2017;40:369-76.

22. Moseley K, Skrabal J, Yano S, Koch R. Sapropterindihydrochloride (6R-BH4) and maternal phenylketonuria: two case studies [J]. Infant Child Adolesc Nutr. 2009;1:262-6.

23. Aldámiz-Echevarría L, Couce ML, Llarena M, Andrade F. A new case of maternal phenylketonuria treated with sapropterindihydrochloride (6R-BH4). Gynecol Endocrinol. 2014;30:691-3.

24. Feillet F, Ficicioglu C, Lagler FB, et al. An Interim Analysis of the Kuvan ${ }^{\oplus}$ Adult Maternal Paediatric European Registry (KAMPER) and Phenylketonuria Developmental Outcomes and Safety (PKU MOMs) Registries: Pregnancies: Presented at the 13th International Congress of Inborn Errors of Metabolism: September 5-8, Rio de Janeiro; 2017.

\section{Publisher's Note}

Springer Nature remains neutral with regard to jurisdictional claims in published maps and institutional affiliations.

Ready to submit your research? Choose BMC and benefit from:

- fast, convenient online submission

- thorough peer review by experienced researchers in your field

- rapid publication on acceptance

- support for research data, including large and complex data types

- gold Open Access which fosters wider collaboration and increased citations

- maximum visibility for your research: over $100 \mathrm{M}$ website views per year

At BMC, research is always in progress.

Learn more biomedcentral.com/submissions 